\title{
To Explore the Protection and Inheritance of Qiang Culture from the Perspective of Institutional Change Theory-Take Mao County as an Example
}

\author{
Wenqiong Ma, Bing Zhao \\ Southwest Minzu University, Chengdu, China \\ Email: 657412844@qq.com
}

How to cite this paper: Ma, W.Q. and Zhao, B. (2019) To Explore the Protection and Inheritance of Qiang Culture from the Perspective of Institutional Change Theory-Take Mao County as an Example. Open Journal of Social Sciences, 7, 126-134. https://doi.org/10.4236/jss.2019.74011

Received: November 9, 2018

Accepted: April 13, 2019

Published: April 16, 2019

Copyright () 2019 by author(s) and Scientific Research Publishing Inc. This work is licensed under the Creative Commons Attribution International License (CC BY 4.0).

http://creativecommons.org/licenses/by/4.0/ (c) (i) Open Access

\begin{abstract}
In the reports of the $19^{\text {th }}$ National Congress of the Communist Party of China, general secretary Xi Jinping pointed out that as the soul of the country and nation, the prosperity of culture means the prosperity of the country and the mightiness of culture also reflects that of the nation. The great rejuvenation of the Chinese nation shall not be achieved without high cultural confidence and cultural prosperity. We should adhere to the cultural development path of socialism with Chinese characteristics, stimulate the creativity of cultural innovation of the whole nation, so as to build a culturally strong socialist country. At the same time, it is also necessary to promote the creative transformation and innovative development of the outstanding traditional culture of China, protect and promote national culture, so as to support the cultural development of ethnic minorities. From the perspective of institutional change, in this paper, strengthening the protection and inheritance of Qiang culture is simply analyzed, in order to complete the modern cultural industry system and market system, push forward the construction of the international communication ability and show a real, tridimensional and comprehensive China by well narrating Chinese stories, finally realizing the enhancement of cultural soft power of China.
\end{abstract}

\section{Keywords}

Qiang Culture, Cultural Confidence, Cultural Prosperity, Cultural Development

\section{Cultural Resources}

The Qiang nationality originated from the ancient Qiang. Known for herding 
sheep, the ancient Qiang people not only are an important part of the Chinese nation, but also have a wide and far-reaching influence on the development of Chinese history and the formation of the Chinese nation. As one of the most ancient ethnic groups in China, the ancient Qiang people mainly lived in the northwest region, so it was called West Qiang at that time. As early as the end of Yangshao culture (about $3000 \mathrm{BC}$ ), the surname of Yan Emperor of the two tribes of Yan and Huang in the Yellow River valley was Jiang, while "Jiang" and "Qiang" were two different forms of the same word, which were often used interchangeably in oracle bone inscriptions. After the Qin and Han dynasties, the Qiang people began to migrate to central plains and the southwest and gradually merged with the Han people after entering central plains. The majority of the Di and Qiang tribes living in Han dynasty is Ran and Mang. After that, Emperor Wudi explored the western region and set up four counties in Hexi, which separated the Hun from the Qiang people, when some of the Qiang people started to go south from Gansu and Qinghai. During the Wei, Jin, Southern and Northern dynasties as well as Sui and Tang dynasties, after two large-scale migrations, Qiang people in the northwest arrived at the upper reaches of the Min River. During the Wei, Jin and Southern and Northern dynasties, the Qiang people in the northwestern areas of Tanchang and Dengzhi once extended their influence to the upper reaches of Min River. In the early Tang dynasty, tribes such as Xifeng, etc., who originally lived among the Dangxiang Qiang people of Hehuang area, went south and resided in areas of Songpan and Mao county. The Jimi state under the military prefecture of Mao state in Tang dynasty was set up to convert the Qiang people's tribes, among which the Tu state was set up for the submission of the Qiang people of Lintu, the Ran state was set up for the submission of the Qiang people of Liancai, while the Zuo state was set up for the submission of the Qiang people of Baigou. Over the past one thousand years, after long-term integration and development, tribes that have successfully migrated to Mao county, Wenchuan, Li county as well as the Di and Qiang tribes of Beichuan area together formed the ancestors of today's Qiang people. Nowadays, Qiang nationality is mainly distributed in Mao county, Li county, Wenchuan, as well as part of Songpan and Heishui, among which, there are mainly Tibetan, Qiang and Han nationalities in Li county, Wenchuan is the intersection of Han and Qiang nationalities, while the Qiang nationality dominates in Mao county. The unique ethnic culture of Qiang nationality has been formed in the long-term historical evolution, covering a series of ethnic cultural forms such as language, costume, handicraft, diet, folk art, sports competition, etiquette and festivals, while a variety of cultural systems such as religious culture, Shibi culture, Dayu culture and red culture have also been formed at the same time [1].

\section{1) Language of Qiang Nationality}

Belonging to the Qiang branch of Tibetan-Burman language of Sino-Tibetan languages, the Qiang language is divided into two major dialects of the south and north, in which the southern dialects are mainly distributed in areas of 
Wenchuan county, Li county, Wenchuan county and Mao county, including Daqishan dialect, Taoping dialect, Longxi dialect, Miansi dialect and Yanmen dialect, while the northern dialects are mainly distributed in most of Mao county, Songpan Qiang area, most of Heishui and Beichuan Qiang Autonomous County, including Qugu dialect, Zhenping dialect, Luhua dialect, Mawo dialect, Zhimulin dialect and Heihu dialect.

\section{2) Traditional Handicrafts}

The handicraft skills of Qiang nationality include Qiang embroidery, paper cutting, silver ornaments, Qiang embroidery clothing, iron ware forging, metal casting processing, woodworking, stone-laying, etc..

Originated from the embroidery of ancient Qiang people, Qiang embroidery has a variety of stitching methods, including cross stitching, admitting stitching, linking stitching, chain button, plain embroidery, etc.. Qiang embroidery has a variety of colors and patterns, most of which reflect natural elements in reality, such as plants, animals and characters full of auspicious connotations. The paper cutting of Qiang nationality mostly reflects the local religious belief and living customs, and it also has a variety of expression techniques, mainly implying the yearning for good lives. With strong ethnic characteristics, the silver ornaments of Qiang nationality is usually used as decoration for the clothing of the women of Qiang nationality, the patterns and carving techniques of which are also diverse.

Traditional Qiang costumes include long linen gowns, sheepskin vests, headscarves, belts and leggings. Men wear knee-length blouses, plaits with headscarves, belts and leggings made of linen or wool, as well as straw, cloth, or oxen boots in general. Women wear long, ankle-length blouses, in which the collar was encrusted with plum-flowered silver, with lace at the lapels, sleeves, and necklines, and embroidered apron and streamers at the waist, with patterned designs on the waistband as well. In the Qiang region, the costumes of different regions are diverse and have distinct characteristics of themselves.

Iron ware forging, also known as forge iron, is mainly used to forge agricultural tools or daily supplies. Ornaments are usually produced through metal casting, the process of which includes punching, hammering, carving, engraving, enchasing, welding, cleaning, etc.. Woodworkers mainly build houses and produce furniture. Carpenters have a variety of tools such as hand planers. In the valley area of the upper reach of Min River, the Qiang people build stone houses and towers.

\section{3) Diet of Qiang Nationality}

The main crops produced in the Qiang area include corn, wheat, potatoes, barley, etc., and there are also various fruits, vegetables and meats being produced at present. The Qiang cuisine also features bacon, edible wild herbs and corn puree. At Qiang, potatoes can be prepared in a variety of ways, such as potato glutinous rice cake, pickled cabbage potato soup, mashed potato, etc..

\section{4) Traditional Competition}

Traditional competitive activities of Qiang nationality include pushrod, egg 
holding, shooting crossbow, Qiangwang chess and torsion stick. Pushrod is a sport between two or more people which combines competition, entertainment and appreciation. At present, it is divided into two types of squat push and bow push. Egg holding is mainly used to exercise people's eyesight and leg strength as well as to cultivate the agility of movements. It is an interesting game that takes a lot of energy and is suitable for ordinary people to gather in the yard dam or on the lawn. As a tool used by the ancestors of the Qiang nationality for survival and defense, crossbows are the crystallization of collective wisdom, while shooting crossbows is a traditional competition activity of the Qiang nationality. Qiangwang chess, known in the Qiang language as Re'e Bazhi, is popular two-player chess approach in the Qiang area for all. Torsion stick is a traditional sport originated since ancient times that is popular among people of all ages.

\section{5) Etiquette and Festivals}

Among Qiang's exclusive festivals, the important ones include Qiang's Calendar Year, Mountain-sacrifice Festival, and the Valerian Festival. Qiang's Calendar Year is on Oct. ${ }^{\text {st }}$ of the lunar calendar every year, the celebration for which usually lasts for 3 to 5 days, and the whole event is hosted by local Shibi. Mountain-sacrifice Festival, also known as the Mountain-Revolving Festival, is held at different times and in different locations to pray for good weather. Valerian Festival, known as the Song-leading Festival, is also the Women's Day of the Qiang nationality, where men shall do the housework while women shall gather to sing and dance. The traditional etiquette and festivals of Qiang nationality with rich folk colors reflect the cultural imprint of ancient times.

\section{6) Culture of Beliefs}

A number of deities are revered by the Qiang people, most of which are natural deities. Among them, except for the deity of fire represented by Guozhuang, all the others are represented by white stones and are widely worshiped. The highest white stone in the middle of the masonry of the Qiang nationality's blockhouse is usually regarded a symbol of the supremacy of Mubita, the deity of heaven, while white stones are also placed on windows and door edges to express the awe of other deities.

The Shibi classics include Shibi singing scripture and Shibi graphic scripture. Among them, the Shibi singing scripture, mainly divided into the upper, middle and lower scriptures, is an encyclopedia spread through words and deeds. The contents of the upper scripture mainly include making and redeeming vows to deities, the middle scripture is mainly on matters related to marriage, while the lower scripture is mainly used to eliminate the evil spirit of the bereaved family when conducting the funeral rites. As a carrier of folk belief, many contents of Shibi classics are related to the religious belief of Qiang nationality. In line with the contents of Shibi classics, the Shibi graphic scripture reflects the social life phenomena of Qiang nationality including nomadic herding, hunting, farming, marriage and funerals.

\section{7) Dayu Culture}

Dayu, born on the western Qiang, is an important cultural ancestor of the 
Chinese people, and is famous for his mastery of water control. Besides the Dayu relics in all areas of Qiang nationality, there are abundant folklores. In July 2017, Dayu ranked among the first batch of 10 historical figures of Sichuan and won the first place. Dayu's devotion spirit of selflessness and benefiting the people, scientific spirit of bold exploration and pragmatic, entrepreneurial spirit of arduous struggle and persevering, as well as the national unity and harmony spirit of unity and common development are symbols of the national spirit of China, and also the cultural highlight of the area.

\section{Explore Paths and Development Prospects from the Perspective of Institutional Change}

The importance to protect history through culture is not only because we can gain knowledge from history, but also because the continuity of various social systems has linked the present, the future and the past. The choices of present and future are shaped by the past, which can only be understood in the historical discourse of institutional evolution [2]. One of the most important improvement steps is to integrate systems into the analysis of economic theories and economic history.

The theory of institutional change. North believes that "the unbalance of the system will lead to the possibility of institutional change, and whether the new system can be realized depends on the game of different social subjects." From the viewpoint of new economic history, institutional change refers to the process of substitution, transformation and transaction of institutions. Effective institutional change constitutes the source of long-term economic growth. As far as the causes of institutional change are concerned, there are not only exogenous variables of political, military, social and even ideological nature, but also internal changes in the outbreak of conflicts of interest among actors within the system. According to the different roles of the power subject in the institutional change, it can be divided into the top-down mandatory change and the bottom-up induced change [3].

\section{1) Cultural Protection Path}

In order to create the International Qiang Culture Experience Area in Aba prefecture and to explore, protect and inherit the local characteristic culture, the local government must adopt timely and appropriate policies for the various problems existing in the Qiang culture area. The local people (especially the young people) should be more familiar with the Qiang culture, while the public should be more aware of the Qiang culture. In addition, it is required to establish a multi-powering culture preservation mechanism of government-led, social participation and market leading, and through media promotion and school education, to activate the vitality of Qiang culture, strengthen the cultural creativity, ensure stock, improve the increment among local people (especially the young people), so as to realize the focused, multi-level and comprehensive development and preservation of cultural resources, taking the path of protection 
with exploitage of cultural heritages.

\section{a) Administrative Cultural Protection System}

Government-dominant cultural relic restoration: As the dominant force in Qiang cultural protection, in terms of cultural protection of the area, the government should give full play to its leading role by introducing professional talent and cultivating directional professionals through cooperating with professional colleges, universities and enterprises, so as to use professional knowledge and skills to repair and manage the physical and cultural heritage of Qiang cultural area. In the protection of Choubian building of Xue Town and the official residence of Wang Taichang, the local government should lead the joint cultivation of professional renovation and protection personnel with relevant colleges and universities, and sign agreements with the trainees, that is, the government shall fund the study, and assign the working place where they shall participate in the protection of cultural relics. As to the existing intact Qiang blockhouses in the yellow mud blockhouse group in Buwa, the government should lead to invite local inheritors of the construction of Qiang's blockhouses to carry out maintenance and repairing, as well as the restoration of the collapsing parts.

Set up cultural relic protection units: Set up cultural relic protection units under the leadership of the local government, classify and sort out the cultural relics in the existing cultural relic protection units of the area, and conduct protection collection, exhibition and publicity; Collect and protect important folk cultural relics and improve the intensity of protection of cultural relics through centralized collection and management. For well preserved ancient ruins, such as the stone-carved slogan left by the Red Army at Sanyuan Bridge, ruins of Jiangwei Town, etc., the cultural relics protection units should introduce relevant policies, and may employ villagers from where the ancient sites locate to supervise and feedback in time, so as to be familiar with relevant situation of key cultural relics protection units, and implement relevant protection measures in the case of geological disaster early warning to ensure the integrity of cultural relics.

Implement cultural protection policy: The relevant departments of the local government should introduce culture protection policy to carry out protection management of the existing cultural heritage, including carrying out the registration and management of tangible cultural heritages, intangible cultural heritages, cultural inheritors, performance forms, performance props, etc. through videos, films and other forms, so as to establish a complete cultural system and has implement different culture protection policies for different cultures. The new cultural, sports and broadcasting bureau of the government and relevant departments should visit cultural relics protection units, intangible cultural heritage inheritors, study houses, museums, etc., and use audio and video to record the multi-vocal folk songs, Qiang language, Dayu legend, Shibi singing scripture and other intangible cultures, and use photos to record the related ancient sites and ancient relics and other material heritages. After being sorted out, 
they will be divided into grades, and the tangible and intangible heritage systems will be established for different levels. The protection policies cover aspects such as protection scope, protection category, protection means, emergency measures and legal provisions, etc..

Cultural inheritance subsidy system: The government should formulate a fund subsidy system for the cultural inheritance of Qiang, so as to guarantee the inheritance of various intangible cultural heritage by providing preferential treatment or subsidies for young people and inheritors of relevant intangible cultural heritage. The criteria for the payment of subsidies shall be determined in the subsidy system, and the amount of subsidies shall be paid monthly or quarterly.

\section{b) Commercial Cultural Protection System}

Build museums with market capital: Facing the problem of the single source of funds for the construction and management of museums of the area, the local government should actively and effectively introduce market capital, so as to realize the marketization of museum operation by building and managing museums with market capital.

Normalize the commercialization of folk customs: As the major participant of cultural protection, relevant government departments should issue relevant norms to prevent the excessive commercialization of folk culture, and ensure the maximization of social benefits of folk culture by standardizing and regulating the commercial generalization. As a national $4 \mathrm{~A}$ scenic spot, the commercial phenomenon of Luobo Village is serious. In order to avoid the excessive commercialization of the area and retain its authenticity, detailed regulations should be made in the government regulations on business model, industry type, business operation scope, business operation time, reward and punishment intensity, and the commercial development period shall be from may to October, while the regional self-improvement period is from November to April.

c) Inheritor Cultural Protection System

Platform lectures: In terms of the inheritance of traditional culture, replace natural inheritance with government providing centralized training for inheritors. The local government, together with colleges and universities and social enterprises, conducts lectures on inheritors to enhance their theoretical knowledge and skills, cultivate their sense of responsibility and participation, and finally enhance the popularity of local traditional culture.

Offer classes and receive disciples: The government will offer study classes on traditional cultures, and hire professional teachers or local well-known inheritors to carry out theoretical and technical training for local existing inheritors and relevant government supervisors, so as to cultivate intangible cultural heritage inheritors and government personnel with strong professional knowledge and skills.

Folk cultural competition: The government or the folk should organize traditional culture competitions on their own initiative. By combining the authenticity and innovation of traditional culture and integrating popular elements, the folk culture products with local characteristics will be created, which will be- 
come the cultural activities with local characteristics and cultivate the cultural consciousness as well.

\section{d) Cultural Protection System of Folk Committees}

Set up cultural protection associations: The local government should take the lead to set up the cultural protection association to invite government personnel, inheritors, experts and scholars to participate in and explore the traditional endangered culture of the area, engage in the protection of local culture, as well as expand the publicity channels and scope of local culture.

Self-assisted protection units: The masses conduct cultural protection spontaneously, so as to build the protection platform of traditional culture by giving play to the subjectivity of the masses. The establishment of rural patrol teams can also improve the recognition of Qiang culture among local people.

\section{2) Development Prospect}

Explore the historical connotation, establish the protection system and build the international brand of Qiang culture by combining the content of the reports of the $19^{\text {th }}$ National Congress of the Communist Party of China, that is, "to deepen the reform of cultural system, complete the cultural management system, and accelerate the establishment of the institutional mechanism that puts social benefits first and integrates social benefits and economic benefits. Complete the public cultural service system, thoroughly implement cultural-benefiting projects, and enrich cultural activities of the people. Strengthen the protection and utilization of cultural relics as well as the protection and inheritance of cultural heritage. Improve the modern cultural industry system and the market system, innovate production and operation mechanisms, complete the cultural and economic policies, and cultivate new cultural formats. Repair and protect the tangible heritages including the stone-carved slogans left by the Red Army at Sanyuan Bridge, Choubian Building, Jiangwei Town, yellow mud blockhouse group in Buwa, the old residence of Luobo Village, the official residence of Wang Taichang, etc., and save the intangible heritages for inheritance such as Qiang language, traditional folk arts, Shibi culture, Dayu culture, etc., as well as strengthen the promotion of local architectural culture and historical culture.

Make the stone-carved slogans left by the Red Army at Sanyuan Bridge the key sketching base of red cultures, the Choubian Building the experiencing ancient street of historical amorous feelings of Qiang cultural area, the Jiangwei Town the key cultural relic visit and popularization spot with historical and cultural heritage, the yellow mud blockhouse group in Buwa the demonstration site for the inheritance and protection of the construction skills of provincial ancient architectures, the old residence of Luobo Village the "Block on the Cloud" integrating historical traditional culture and diversified cultures, and the official residence of Wang Taichang the well-known provincial ancient architectural attraction with traditional cultural characteristics.

Through implementing the comprehensive and sustainable development strategy of the intangible culture of Qiang nationality, achieve the full coverage of Qiang language among internal communication within the Qiang area, the 
popularization of multi-vocal folk songs, the classic of the inheritance of Shibi culture, as well as the unique display of Dayu culture.

\section{Fund Project}

This project has been funded by the Southwest Minzu University Nationalities Graduate Innovative Research Project (Project Name: To Explore the Protection and Inheritance of Qiang Culture from the Perspective of Institutional Change Theory-Take Mao County as an Example, Project No.: CX2018SZ143).

\section{Conflicts of Interest}

The authors declare no conflicts of interest regarding the publication of this paper.

\section{References}

[1] Detailed Planning of Ancient Qiang Town in Mao County (2009).

[2] Basic Requirements for the Protection and Development of Traditional Villages (Trial) (2013).

[3] Institution, Institutional Change and Economic Performance Douglas North. 